\title{
Determination of Ferritin Level and Total Iron Binding Capacity in Pregnancy and Postpartum Subjects in Owerri
}

\author{
Okoroiwu Ijeoma Leticia ${ }^{1}$,Obeagu Emmanuel Ifeanyi ${ }^{2}$, Elemchukwu \\ Queen ${ }^{3}$,Ochei Kingsley Chinedum ${ }^{4}$ \\ 1. Lecturer (P.hD), Department of Medical Laboratory Science, Faculty of Health Science, Imo State \\ University, Owerri, Nigeria. \\ 2. Diagnostic Laboratory, University Health services Department,Michael okpara University of \\ Agriculture, Umudike, Nigeria, \\ 3 Rivers State College of Health Science and Technology, Port Harcourt \\ 4.Department of Medical Laboratory Science,Ambrose Alli University, Ekpoma Edo State,Nigeria
}

\begin{abstract}
This study was carried out to determine the ferritin level and total iron binding capacity in pregnancy and postpartum. The study was carried out at federal medical center Owerri (FMC). Sixty (60) samples were used for the study, thirty (30) pregnant women and (30) thirty postpartum women were studied. Serum iron and TIBC were determined using standard haematological method. The results obtained were

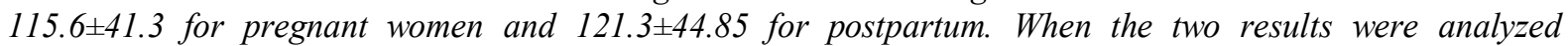
statistically, there is a statistical significant difference between the two $p<0.05$. The results obtained in TIBC were $265.3 \pm 79.1$ for pregnant women and $473.5 \pm 82.6$ for postpartum women. When the two results were analyzed statistically there is a statistical significant difference between the two $P<0.05$. From this study, there is a statistical significant decrease in serum iron for pregnant women (115.6 \pm 41.3$)$ than in postpartum women (121.3 \pm 44.85$) P<0.05$. And also a statistical significant decrease in TIBC for pregnant women (265.3 \pm 79.1$)$ than in postpartum women (473.5 \pm 82.6$) P<0.05$.
\end{abstract}

Keywords: Pregnancy, haematological, Serum iron, ferritin level and TIBC.

\section{Introduction}

Iron is a component of a number of proteins including haemoglobin, myoglobin, cytochromes and ezymes involved in redox reactions. Haemoglobin is important for transport of oxygen to tissues throughout the body (Bothwell et al., 1979). Iron can exist in a range of oxidation states. The interconversion of those various oxidation states allows iron to bind reversibly to ligands such as oxygen, nitrogen and sulphur atoms. Almost two thirds of the body's iron is found in haemoglobin in circulating erythrocytes (Dewey et al., 2002). About a quarter of the body's iron is found in readily metabolized stores as ferritin or haemosiderin in the liver and reticulo-endothelial system. The remaining iron is in the myoglobin of muscle tissue and a variety of enzymes necessary for oxidative metabolism and other cell function (Bothwell et al., 1979). The iron content of the body is highly conserved (Bothwell et al., 1979). To achieve iron balance, adult men need to absorb about $1 \mathrm{mg}$ per day and adult menstruating women about $1.5 \mathrm{mg}$ per day, although this is highly variable. Towards the end of pregnancy, the absorption of 4-5mg per day is necessary (WHO 2001). Requirements are higher during periods of rapid growth in early childhood and adolescence (WHO, 2001). Inadequate intake can lead to varying degrees of deficiency, from low iron stores (as indicated by low serum ferritin and a decrease in iron-binding capacity), to early iron deficiency and iron deficiency anaemia.

Total Iron Binding Capacity (TIBC)

TIBC is a medical laboratory test that measured the blood's capacity to bind iron with transferrin. It is performed by drawing blood and measuring the maximum amount of iron that it can carry, which indirectly measures transferring (Yarianishi et al, 2003) since transferrin is the most dynamic carrier. TIBC is less expensive than a direct measurement of transferrin (Kasvosve et al, 2002, Gambling et al, 2009). The TIBC should not be confused with the (UIBC) unsaturated iron binding capacity. The UIBC is calculated substracting the serum iron from the TIBC.

\section{FERRITIN}

Ferritin is a ubiquitous intracellular protein that stores iron and releases it in a controlled fashion. The protein is produced by almost all living organisms, including algae, bacteria, higher plants and animals. In humans, it acts as a buffer against iron deficiency and iron overload. Ferritin is found in most tissue as a cytosolic protein, but small amount are secreted into the serum where it functions as an iron carrier. Plasma ferritin is also an indirect marker of the total amount of iron stored in the body; hence serum ferritin is used as a diagnostic test for iron deficiency anaemia (Weng et al., 2010). 
Ferritin is a globular protein complex consisting of 24 protein subunits presenting in every cell type. Ferritin that is not combined with iron is called apoferritin

\section{Importance of Iron and need of Iron in pregnancy and postpartum}

Iron is an essential nutrient at every stage of life-it is a critical component of protein such as enzymes and haemoglobin. Almost two-thirds of iron in the body is the haemoglobin present in circulating red blood cells. Haemoglobin moves oxygen to the tissues for metabolism. During pregnancy, women need more iron to support the increased maternal red blood cell mass. This supplies the growing foetus and placenta, and support normal brain development in the foetus. In the third trimester of pregnancy the foetus builds iron stores for the first six months of life (Fernandez-Ballart, 2000). The increased demand for iron is not spread evenly over the course of pregnancy. In the first trimester, iron requirement are partially met through the cessation of menstruation, saving $0-56 \mathrm{mg}$ of iron per day (WHO, 2001). In the second and third trimesters, iron demand increases significantly. Approximately $450 \mathrm{mg}$ of iron is required for the $35 \%$ increase in red blood cell mass that occurs during pregnancy (WHO, 2001). However, this iron requirement does not affect long-term iron balance because iron is recovered from the extra red blood cells and returned to the body stores at the end of pregnancy (WHO, 2001). Additionally, supplementing well nourished pregnancy women with $20 \mathrm{mg}$ of iron per day has been shown to be effective in reducing the prevalence of iron deficiency and iron deficiency anaemia at the time of delivery (Maklides et al, 2003).

\section{Outcome of Deficiency or Reduction in Ferritin and TIBC}

Reduced ferritin and TIBC are associated with negative outcomes during pregnancy and postpartum, including increased risk of haemorrhage, sepsis and maternal mortality (Schumann et al, 1998). Women who are ferritin and TIBC deficient suffers from iron deficiency anaemia during the first two trimesters and are twice as likely to deliver early, have three times the risk of having a low birth weight infant (Janis, 2012) and an increased risk of having and infant small for gestation age.

Postpartum ferritin and TIBC deficiency is common (Waldmann et al., 2004) and anaemia cause by this has been linked with the following consequences:-

- Increased risk of postnatal depression (Hurrell et al., 2010).

- Increased prevalence of urinary tract infections (Ott et al., 2012).

- $\quad$ Fatigue and exhaustion (Warsh et al., 2013)

- Insufficient risk syndrome.

- $\quad$ Reduced breast milk quality (Rimon et al., 2005).

\section{RESEARCH JUSTIFICATION}

Many studies have found out that iron requirement during pregnancy are important and deficiency of these may present serious health and functional consequences. Pregnant women are at high risk for iron deficiency because of increased iron needs during pregnancy (Berymann, 2005). Studies related to anaemia in pregnancy have been carried out in so many areas of the world but much work has not be done on the above topic. "Determination of ferritin level and total iron binding capacity in pregnancy and postpartum subjects in Owerri". This work is therefore meant to fill this vaccum,to access the differences between the values of the subjects in question. And to compare the values of ferritin and total iron binding capacity of pregnant women and postpartal.

\section{AIMS AND OBJECTIVES}

To compare the values of ferritin level and total iron binding capacity of pregnant women and postpartal.

\section{STUDY AREA}

\section{Materials And Methods}

The study was carried out in Owerri, the capital city of Imo State, in Nigeria. It is located in latitude $5^{0}$ $29^{\prime} \mathrm{O}$ ' $\mathrm{N}$ and longitude $7^{0} 2$ ' “ $\mathrm{O}$ E. it has an estimated population of about 400,000 and is approximately 40 square miles $\left(100 \mathrm{~km}^{2}\right)$ in area.

\section{STUDY POPULATION AND SAMPLE SIZE}

A total of 60 women of child bearing age were enrolled in the study (30) thirty pregnant women and (30) thirty postpartal. The pregnant women were referred to Federal Medical Center and those with complication were excluded in the study.

\section{CONSENT}

Ethical approval was obtained from the management of Federal Medical Center Owerri and written consent was received by all participants from the hospital management. An introduction letter obtained from the medical Laboratory department and detailed proposal of the researched work were presented to hospitals whose patients were used to perform the research work. 


\section{Sample Collection}

\section{Methodology}

Precautions were taken on proper collection and processing of blood samples. $5 \mathrm{mls}$ of blood was drawn from the patients arm and put into plane bottles. It was allowed to clot before separating serum from the whole blood. Plastic syringes were used in the collection of whole blood.

\section{Principle of Serum Ferritin}

The iron serum is dissociated from its Fe (iii) transferrin complex by the addition of an acidic buffer containing hydroxylamine. This addition reduces the Fe (iii) to Fe (ii). The chromogenic agent, ferene, forms a highly coloured .Fe (ii) complex that is measured photometrically at 560mm (Tietz et al, 1976).

\section{Principle of Unsaturated iron binding Capacity}

The unsaturated iron binding capacity (UIBC) is determined by adding Fe (ii) iron to serum so that they bind to the unsaturated iron binding steps on transferrin. The excess Fe (ii) iron is reacted with ferrozine to form the colour complex, which measured photometrically. The difference between the amount of $\mathrm{Fe}$ (ii) added and the amount of Fe (ii) measured represents the unsaturated iron binding. The total iron binding capacity (TIBC) is determined by adding the serum iron to the UIBC value (Tietz et al., 1976).

\section{Procedures}

\section{Serum Iron}

1) Test tubes were labeled using 'blank' 'standard' and 'test'.

2) $2.5 \mathrm{mls}$ of iron buffer reagent was added to all the tubes.

3) $0.5 \mathrm{ml}(500 \mathrm{mls})$ of sample was added to respective tubes and mixed.

4) $500 \mu 1$ of iron free water was added to blank.

5) Spectrophotometer was zeroed at $560 \mathrm{~nm}$ with the reagent blank.

6) The absorbance of all tubes was read and recorded ( $\mathrm{A}_{1}$ reading).

7) $0.5 \mathrm{ml}$ of iron colour reagent was added to all the tubes and was mixed.

8) All tubes were placed in a heating bath at $37^{\circ} \mathrm{c}$ for 10 minutes.

9) Spectrophotometer was zeroed at $560 \mathrm{~nm}$ with the reagent blank (Wave length range $520-560 \mathrm{~nm}$ ).

10) Absorbance of all the tubes was read ( $\mathrm{A} 2$ reading).

\section{Unsaturated Iron Binding Capacity}

1) All tubes were labeled using "blank", "standard", and "Test".

2) $2.0 \mathrm{mls}$ of UIBC buffer reagent was added to all tubes.

3) $1.0 \mathrm{ml}$ of iron-free water was added to the blank and mixed.

4) $0.5 \mathrm{ml}(500 \mathrm{ml})$ iron-free water plus $0.5 \mathrm{ml}(500 \mathrm{ml})$ iron standard were added to the test and mixed.

5) Spectrophotometer was zeroed at $560 \mathrm{~nm}$ with reagent blank.

6) The absorbance of all tubes was read and recorded $\left(\mathrm{A}_{1}\right.$ reading).

7) $0.5 \mathrm{ml}(500 \mathrm{ml})$ of iron colour reagent was added to all tubes and mixed.

8) All tubes were placed in a heating bath at $370 \mathrm{c}$ for 10 minutes.

9) Spectrophotometer was zeroed at $500 \mathrm{~nm}$ with reagent blank.

10) The absorbance of all tubes was read and recorded ( $A_{2}$ reading).

\section{Result}

A total of thirty (30) pregnant and thirty (30) postpartum women were studied. The result of ferritin and TIBC level are presented in the table below.

Table 4.1: Showing the result of ferritin and TIBC level of pregnant and postpartum women.

\begin{tabular}{|c|c|c|c|}
\hline Parameter(s) $\mu \mathrm{g} / \mathrm{dl}$ & Pregnancy & Postpartum & P-value \\
\hline Serum iron & $115.6 \pm 41.3$ & $121.3 \pm 44.85$ & $P<0.05$ \\
\hline TIBC & $265.3 \pm 79.1$ & $473.5 \pm 82.6$ & $P<0.05$ \\
\hline
\end{tabular}

Result obtained in serum iron $115.6 \pm 41.3$ for pregnant women and $121.3 \pm 44.85$ for postpartum women. When the two results were analysed statistically, there is a statistical significant difference between the two $\mathrm{P}<0.05$. In TIBC, the results obtained were $265.3 \pm 79.1$ for pregnant women and $473.5 \pm 82.6$ for postpartum women. When the two results were analyzed statistically, there is a statistical significant difference between the two $\mathrm{P}<0.05$.

\section{Discussion}

This research work was carried out to determine the ferritin level and total iron binding capacity in pregnancy and postpartum. The results obtained in serum iron were 115.6 \pm 41.3 for pregnant women and 121.3 \pm 44.85 for postpartum women. In TIBC, the result obtained were $265.3 \pm 79.1$ for pregnant women and 
$473.5 \pm 82.6$ for postpartum women. From the results obtained in serum iron, $115.6 \pm 41.3$ for pregnant women and $121.3 \pm 44.85$ for pregnant women and also in TIBC, $265.3 \pm 79.1$ for pregnant women and $473.5 \pm 82.6$ for postpartum women. When the two results were analyzed statistically, there is a statistical significant decrease in serum iron and TIBC in pregnant women when compared to postpartum women; this is in agreement with the work of (Berymann, 2005) that pregnant women are at high risk for iron needs during pregnancy. During

pregnancy, a woman's iron requirement increase three fold to support the growth of the fetal placenta unit and increased red-cell mass (Michael et al., 2008), meeting this demand requires a diet high in bioavailable iron during pregnancy, but also stored iron levels of at least 300mg before pregnancy (WHO, 2001). Iron deficiency during pregnancy and postpartum can lead to serious consequences for both mother and child (Schumann et al., 1998, Hurrell et al., 2010). There is a less risk of iron deficiency in postpartum, this is in agreement with that women before and after delivery take iron supplement and diet high in bio available iron to favour their iron status. A daily supplements containing 16 to $20 \mathrm{mg}$ of iron is recommended during pregnancy and postpartum. Based on the results of the modeling process, it was concluded that a supplement of $16 \mathrm{mg}$ per day throughout pregnancy would be effective and safe for pregnant women who are in good health. When added to the iron they get from mixed diet, these women would have all they need for pregnancy .

\section{Conclusion}

Iron play an important role in haemostasis, thus pregnant women should be properly screened for serum iron and TIBC in order to avoid iron deficiency anaemia.

The diet of women should contain sufficient bioavalable iron to meet the iron needs during pregnancy. Approximately $450 \mathrm{mg}$ of iron is required for $35 \%$ increase in red cell mass that occurs during pregnancy.

It is therefore essential that iron deficiency is identified early and adequately treated before resulting in iron deficiency anaemia.

\section{References}

[1]. Auerbach, Ballardad H., (2010). Clinical use of intravenous iron-Administration, efficacy, and safety Haematlogy.

[2]. Berymann, C., (2005). Iron Defiency and anaemia in pregnancy: Modern aspects of diagnosis and therapy. Fur. J. Obstet Gynecol Reprod. Biol. 123(2):3-13.

[3]. Bothwell TH, Charltom Rw, Cook JD, Finch CA, (1979). Iron metabolism in man. Oxford Blackwell Scientific.

[4]. Dewey, K.G, Domellof, M., Cohen, C.j Landa Rivera L., Hernel, O., Lanna-dal, B., (2002). Iron supplementation affects growth and morbidity of breast-fed infants: results of a randomized trial in Sweden and Honduras. Jur. Nutri.

[5]. Fernandez- Ballart, J. (2000). Iron metabols during pregnancy. Clin. Drud Invest. 19 (1): 9-19.

[6]. Gambling L., Czopek, A., Anderson HS, et al.,(2009). Fetal iron status regulates maternal iron metabolism during pregnancy in the rat. Am. Journal Physiol. 296: 1063-70.

[7]. Hurrell, R., Egli, I., (2010). Iron bioavailability and dietary reference values. Am. J. Clin. Nutr.

[8]. Janis M., (2012) Supportive oncology iron Deficiency Anaemia in concer patients. Onco. Haematol. 8(2): 74-80.

[9]. Kasvosve, I., Delanghe, J., (2002). Total iron binding capacity and transferrin concentration in the assessment of iron status" clin. Chem. Med. Lab. 40(10): 1014-8

[10]. Maklides, M., Crowther, C.A., Gibson, R.a., Gibbson, R.S., Skeaff, C.M., (2003). Efficiency and tolerability of low dose iron supplements during pregnancy: a randomized controlled trial. Am. Jur. Clin. Nutri. 78 (1):145-53.

[11]. Michael, Alleye, Mc Donald, K., Horne, MDb, Jeffery, L., Miller, M. (2008). Individualized treatment for iron deficiency anaemia in adults. Am. J. Med. 121(11): 943-948.

[12]. Ott, C., Liebold, A., Taises, A Strauch, UG., Obermeier, F., (2012) High prevalence but insufficient treatment of iron deficiency anaemia in patients with inflammatory bowel disease: results of a population -based cohort. Gastroerol Res pract. 59 (5): 9-70

[13]. Rimon, E., Kagansky, N., Kagansky m. et al., (2005).Are we giving too much iron? Low-dose iron therapy is effective in Octogenarians. Am. J. Med. 118(10): 1142-7

[14]. Schumann K., Elsenhans, B., Maurer, (1998). Iron supplementation. J. Trace flem med Biol. 12(3): 129-40.

[15]. Tietz, N.W. (1976). Fundamentals of clinical chemistry Philadelphia, W.B., Saunders, pp. 923-929.

[16]. Waldmann, A., Koschizke JN, Lestmann, C., Hahn, A., (2004). Dietary iron intake and iron status of German female Vegans: results of the German vegan study. Am. Nutr. Med. 48(2):103-8

[17]. Warsh, S., Byrnes, J., (2013). Emerging causes of iron deficiency anaemia refractory to oral iron supplemtation. World K Gastrointest. Pharmacol ther. 4(3):49-53.

[18]. Weng, CH., Chen, JB, Wang, J., Wu CC, TU.Ylin T.H., (2011).” Surgically Gureble No-iron Deficiency Microcytic Anaemia. Castleman's Disease Onkologie 34(8-9): 456-8

[19]. World Health Organization (2001). Iron deficiency anaemia. Assessment, prevention and control. Aguide for programme managers, 114.pn DS, Miller KG, (2008). Nutritinal counseling for vetarians during pregnancy and lactations midwifery womens health. 53(1): $37-44$.

[20]. Yamanishi H., Lyama s., Yamaguchi Y., Kanakura Y., Iwatani Y., (2003).”Total iron binding capacity calculated from serum transferrin concentration or serum concentration and unsaturated iron-binding capacity" Chem. 49 (1): 175-8. 